\title{
Assessment of in situ nest decay rate for chimpanzees (Pan troglodytes ellioti Matschie, 1914) in Mbam-Djerem National Park, Cameroon: implications for long-term monitoring
}

\author{
Serge Alexis Kamgang ${ }^{1,2,6}$ (D) Tuneu Corral Carme ${ }^{3} \cdot$ Kadiri Serge Bobo $^{4} \cdot$ Ekwoge Enang Abwe $^{5}$. \\ Mary Katherine Gonder ${ }^{5}$ Brice Sinsin ${ }^{6}$
}

Received: 22 October 2018 / Accepted: 8 October 2019 / Published online: 28 October 2019

(c) The Author(s) 2019

\begin{abstract}
Accurate assessment of great ape populations is a prerequisite for conservation planning. Indirect survey methods using nest and dung, and a set of conversion parameters related to nest decay rates, are increasingly used. Most surveys use the standing crop nest count (SCNC) method, whereby nests are counted along transects and the estimated nest density is converted into chimpanzee density using an often non-local nest decay rate. The use of non-local decay rate is thought to introduce substantial bias to ape population estimates given that nest decay rates vary with location, season, rainfall, nest shape, and tree species used. SCNC method has previously been applied in Mbam-Djerem National Park (MDNP) in Cameroon, for chimpanzee surveys using a non-local nest decay rate. This current study aimed to measure a local nest decay rate for MDNP and implications for chimpanzee population estimates in the MDNP. The mean nest decay rate estimated using a logistic regression analysis was 127 [95\% CI (100-160)] days. Moreover, the results suggested that rainfall strongly influenced the nest decay rate over the early stage of the lifetime of the nests. The study confirms that estimates of chimpanzee density and abundance using non-local decay rates should be treated with caution. Our research emphasized the importance of using local nest decay rates and other survey methods which do not depend on decay rates to obtain more accurate estimates of chimpanzee densities in order to inform conservation strategies of these great apes in MDNP.
\end{abstract}

Keywords Mbam-Djerem National Park $\cdot$ Local nest decay rate $\cdot$ Chimpanzee density $\cdot$ Indirect survey $\cdot$ Conservation strategies

\section{Introduction}

The Congo Basin rainforest is the second largest wilderness area on the planet after the Amazon (De Wasseige et al. 2012), representing $70 \%$ of the African forest cover

Electronic supplementary material The online version of this article (https://doi.org/10.1007/s10329-019-00768-3) contains supplementary material, which is available to authorized users.

Serge Alexis Kamgang

sergekamgang@gmail.com

1 Garoua Wildlife School, Face aéroport International de Garoua, PO Box 271, Garoua, Cameroon

2 Ministry of Forestry and Wildlife, Yaoundé, Cameroun

3 Department of Animal Biology, Plant Biology and Ecology, Autonomous University of Barcelona, Bellaterra, 08193 Barcelona, Spain
(Guinness 2010) and sheltering most populations of African great apes (Fruth and Hohmann 1996; Williamson et al. 2013). This forest and the fauna inhabiting it are threatened by habitat loss, fragmentation, bushmeat hunting, climate change, emerging infectious diseases, and other activities such as logging and mining (Huijbregts et al. 2003; Walsh et al. 2003; Bermejo et al. 2006; Hart et al. 2008; Spehar et al. 2010; Wevers et al. 2011; IUCN 2014; Katsis

4 Department of Forestry, Faculty of Agronomy and Agricultural Sciences, University of Dschang, PO Box 222, Dschang, Cameroon

5 Department of Biology, Drexel University, Philadelphia, PA 19104, USA

6 Laboratory of Applied Ecology, Faculty of Agricultural Science, University of Abomey-Calavi, 01, PO Box 526, Cotonou, Bénin 
et al. 2018; Hicks et al. 2010), which are exacerbated by poverty and pervasive corruption (Walsh et al. 2003; Hart et al. 2008). As a consequence of all these factors, great ape populations have experienced a precipitous decline within the last 40 years (Fruth and Hohmann 1996; Walsh et al. 2003; Williamson et al. 2013). Thus, large-scale conservation measures are needed urgently in order to avoid further decline of great ape populations as well as to mitigate the various threats (Spehar et al. 2010; Cameron et al. 2016).

The common chimpanzee (Pan troglodytes, Blumenbach 1799) has the largest geographic distribution of all nonhuman great ape species and is located discontinuously from southern Senegal across the forested belt north of the Congo River to western Tanzania and western Uganda (Williamson et al. 2013; IUCN 2014; Humle et al. 2016). Four subspecies are recognized: the western chimpanzee (P. t. verus, Schwarz 1934), the Nigeria-Cameroon chimpanzee (P. t. ellioti, Matschie 1914), the central chimpanzee (P.t. troglodytes, Blumenbach 1799), and the eastern chimpanzee (P. t. schweinfurthii, Giglioli 1872) (Gonder et al. 2006; Gonder et al. 2009; Prado-Martinez et al. 2013). With less than 9000 wild individuals remaining, P. t. ellioti, the focal subspecies of this study, has the smallest geographic range and the smallest population size of all chimpanzee subspecies (Gonder et al. 1997; Caldecott and Miles 2005; Morgan et al. 2011). All four chimpanzee subspecies are classified as Endangered by the IUCN Red List of threatened species (Oates et al. 2016). Given its more limited geographical distribution and numbers, $P$. t. ellioti merits more urgent conservation action (Morgan et al. 2011).

An effective management of chimpanzees requires an accurate understanding of their population status including density, abundance, distribution, threats, and population trends in order to prioritize strategies needed for their conservation (Kühl 2008; Kalan et al. 2016; Morgan et al. 2011). Chimpanzees are elusive and most populations are assessed indirectly using nest counts (Plumptre 2000; Laing et al. 2003; Kühl 2008; Spehar et al. 2010; Head et al. 2013; Hicks et al. 2014; Howe et al. 2017; Kamgang et al. 2018). In all great ape species, each weaned individual builds each evening a nest made of leaves, branches, and other vegetal material in which to spend the night (Tutin and Fernandez 1984). Nests provide comfort, thermoregulation, and protection against predators and parasites (Kingdon and Largen 1997; Anderson 2000; Pruetz et al. 2008; Stewart et al. 2011; Koops et al. 2012; Samson and Hunt 2012). These nests can remain intact from a few days to several months (Tutin and Fernandez 1984; Mathewson et al. 2008) and have thus been used to ascertain the presence and estimate the population of chimpanzees.

Over the past decades; circumstantial evidence (usually animal dung and nests) has been increasingly used in wildlife surveys (Krebs 1989; Vernes 1999; Laing et al. 2003; Walsh and White 2005; Nzooh et al. 2015; Nzooh et al. 2015). Nest or dung surveys have been used to estimate abundance for several mammal species such as bonobos Pan paniscus (Serckx et al. 2014), western lowland gorillas Gorilla gorilla (Walsh and White 2005; Haurez et al. 2014; Tsakem et al. 2015), Bornean orangutans Pongo pygmaeus (Mathewson et al. 2008; Spehar et al. 2010), African elephants Loxodonta cyclotis (Fay 1991; Barnes et al. 1997; Nchanji and Plumptre 2001; Barnes and Dunn 2002; Jathanna et al. 2015), European deer Capreolus capreolus, and kangaroos Macropus rufus (Vernes 1999).

The standing crop nest count (SCNC) method is typically used to estimate chimpanzee densities from nest counts along transects. In this method, nests are surveyed once and nest density is converted to population density estimates using a production rate and a nest decay rate (Tutin and Fernandez 1984; Morgan et al. 2006). The nest creation rate can be obtained by direct monitoring of habituated chimpanzees (Tutin and Fernandez 1984), while estimating nest decay rate in unhabituated populations requires more time and resources, and involves monitoring a sufficient number of fresh nests from the time they are built to the time they disappear (Plumptre and Reynolds 1996). Most surveys use a non-locally-acquired nest decay and production rate, although these two parameters are not reliably comparable across sites (Laing et al. 2003; Buij et al. 2003; Kühl 2008), as nest decay rates might be affected by a number of local factors such as climatic conditions, habitat type, and plant species used to build the nests (Laing et al. 2003; Maisels et al. 2009; Singleton 2009; Stokes et al. 2010). The SCNC method to estimate great ape densities is financially affordable for most protected areas, but few studies on nest production and decay rates have been conducted (Plumptre and Reynolds 1996; Morgan et al. 2006).

In comparison, the mark nest count method does not use the nest decay rate but it takes into account the length of time between survey intervals (Mathewson et al. 2008; Spehar et al. 2010; Ndimbe et al. 2013). All nests are counted and marked during the first survey and on subsequent surveys only new nests are counted and marked. However, the time interval between two consecutive surveys should be shorter than the minimum time for the nest to disappear (Hashimoto 1995; Plumptre and Reynolds 1996). Several surveys have been carried out in the MDNP to estimate chimpanzee abundance (Maisels et al. 2000, 2009; Kamgang et al. 2018). However, all of these previous surveys used the SCNC method with a non-locally acquired nest decay rate, which may not give a robust estimate of chimpanzee densities in the MDNP.

Therefore, our study aimed to assess the local nest decay rate of chimpanzees in the core area of the MDNP, as well as to detect some of the environmental factors influencing nest decay rates. As no assessment of nest decay rates has been 
conducted previously in this area, our research was essential to achieve more precise estimates of $P$. $t$. ellioti density and to shape effective management practices for long-term monitoring in the MDNP.

\section{Methods}

\section{Study area}

The forest-savannah transition zone in central Cameroon is of high importance as it preserves interconnecting corridors between populations of the two chimpanzee subspecies (P. $t$. ellioti and P. t. troglodytes), which gives the region a unique importance (Mitchell et al. 2015). This region includes the $\operatorname{MDNP}\left(5^{\circ} 72^{\prime} \mathrm{N}, 12^{\circ} 68^{\prime} \mathrm{E}\right)$, which extends $4165 \mathrm{~km}^{2}$, with a core zone of $1662 \mathrm{~km}^{2}$ and is the largest protected area of forest-savannah mosaic habitat in Cameroon (Bobo et al. 2006; WCS 2017). About half of the park in the southern sector is covered by lowland tropical forest and the other half, in the northern sector, is covered by Sudano-Guinean tree and woodland savannah with a wide forest-savannah mosaic in between, which promotes a very high level of biodiversity (White 1983; WCS 2017). The climate in this region has two seasons: a rainy season from mid-April to mid-October, and a dry season from mid-October to midApril (MINFOF 2007; Abwe et al. 2019). The relief is nearly flat, with a north-to-south altitudinal decline from 930 to $650 \mathrm{~m}$ asl (Bobo and Weladji 2011). The park is drained by the Djerem River, which serves as a permanent water source for wildlife and more than 74 human communities around the park. Human activities such as poaching, illegal logging, and illegal grazing are among the main threats to the wildlife in the MDNP landscape (Bobo and Weladji 2011; WCS 2017). The study site was chosen based on information previously gathered on chimpanzee nest abundance and distribution in the core zone of the MDNP (Maisels et al. 2000, 2009; Kamgang et al. 2018) (Fig. 1).

\section{Data collection}

Nest decay rate can be calculated by either the prospective or the retrospective method (Laing et al. 2003; Stokes et al. 2010; Dutton 2012). The prospective method consists of marking fresh nests at a given time and revisiting them at regular intervals until they disappear (Mathewson et al. 2008). This method may lead to bias if seasonal fluctuations exist in nest decay rates (Laing et al. 2003). In contrast, the retrospective method, which we used in the current study, consists of marking fresh nests at different periods of time and revisiting them only once in order to verify whether or not they have decayed. It is expected that during the revisit, the number of nests remaining from the first visit will be fewer than those marked later. Using this technique, a period of time for a visit is preselected and the mean decay rate of the nests already present can be estimated (Laing et al. 2003; Mathewson et al. 2008).

\section{Nest marking}

We carried out 2-week surveys monthly between January 2016 and March 2017. During this period, we patrolled areas
Fig. 1 The Mbam-Djerem National Park showing the surrounding villages and the locations where chimpanzee nests were marked in the core zone

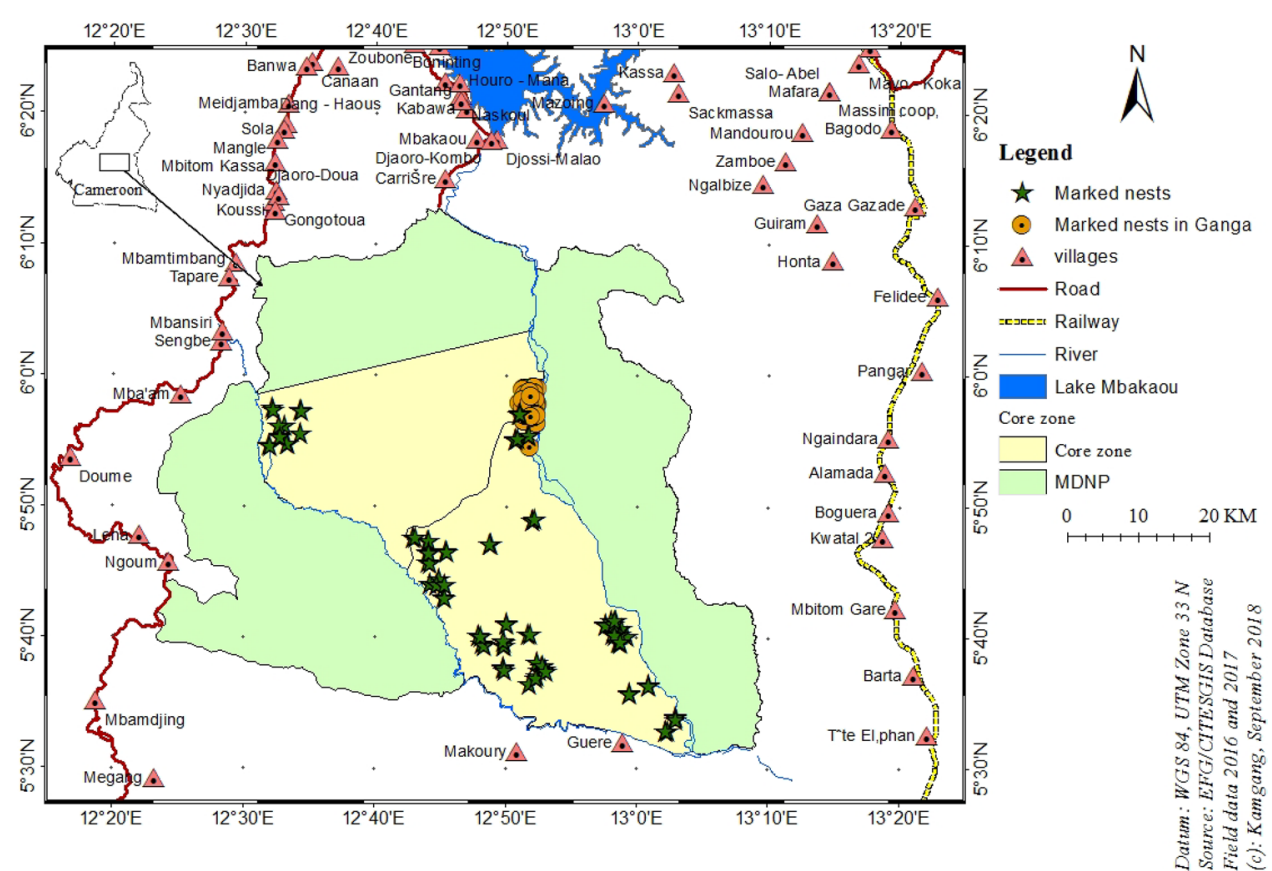


of high activity for chimpanzee in the core zone to locate and mark fresh chimpanzee nests (less than $24 \mathrm{~h}$ old). All nests were marked with codes referring to the survey number ( $\mathrm{S} 1$, $\mathrm{S} 2, \ldots, \mathrm{S} 6)$, the nest group (G1, G2,.., Gn) and the number of marked nests of the same group $(\mathrm{N} 1, \mathrm{~N} 2, \ldots, \mathrm{Nn})$. We also marked other fresh nests as we walked transects during biomonitoring activities in 2016 (Kamgang et al. 2018). For each nest marked nest and nesting site, we recoded the following information: (1) date, (2) vegetation type (gallery forest, colonizing forest or savannah), (3) geographic coordinates, (4) topography of the site (flat, gentle or steep), and (5) total rainfall during the first month of the nest's lifetime.

\section{Rainfall data}

Rainfall data over the same time period as the study were obtained from the Wildlife Conservation Society office at Mbakaou, at the northern edge of the MDNP (Abwe et al. 2019). For each nest marked, we considered the rainfall of the same month the nest was built. We then plotted the climate graph showing rainfall variation in 2017 (Fig. 2).

\section{Revisiting marked nests}

We revisited all marked nests once (Supplementary File 1) to attest whether or not they were still present. We marked nests that were present as (1) and those that were absent as (0) (Supplementary File 2). We considered a nest absent when we were no longer able to identify its structure, that is, the leaves had all decayed and only the framework remained visible (Van Schaik et al. 1995; Plumptre and Reynolds 1996; Buij et al. 2003) (Supplementary File 3).

\section{Data analysis}

We used the software programme QGIS 3.2 Bonn to map the geographic location of all marked nests in the study area (Fig. 1). We conducted a logistic regression in $\mathrm{R}$ to estimate the mean nest decay rate (Laing et al. 2003; Mathewson et al. 2008; Nzooh et al. 2015). We considered only two variables in this analysis: the predictor variable "age" and the response variable "absence/presence". This model allowed us to plot the logistic regression curves of the nest age and to determine the number of days needed for $50 \%$ of the nests to be considered decayed (Eq. 1).

$P\left(Y=\frac{1}{X_{i}}\right)=\frac{e^{\alpha+\beta X+\alpha_{i}}}{1+e^{\alpha+\beta X+\alpha_{i}}}$,

where $\alpha$ is a constant and $\beta$ the coefficient of time, and $X$ representing the time (days).

We tested three logistic regression models in order to reduce the residual deviance following transformation of the predictor variable: the first model (Model 1) used nontransformed data, the second model (Model 2) used the negative-inverse transformation and the third model (Model 3) considered the negative-reciprocal-root transformation. We did not use the logarithmic transformation in this analysis, since sometimes it generates problems when fitting the upper tail of the logistic regression curve, which may result in a biased estimation of the mean nest decay rate (Laing et al.
Fig. 2 Climate graph of the MDNP over the period of the study (2017)

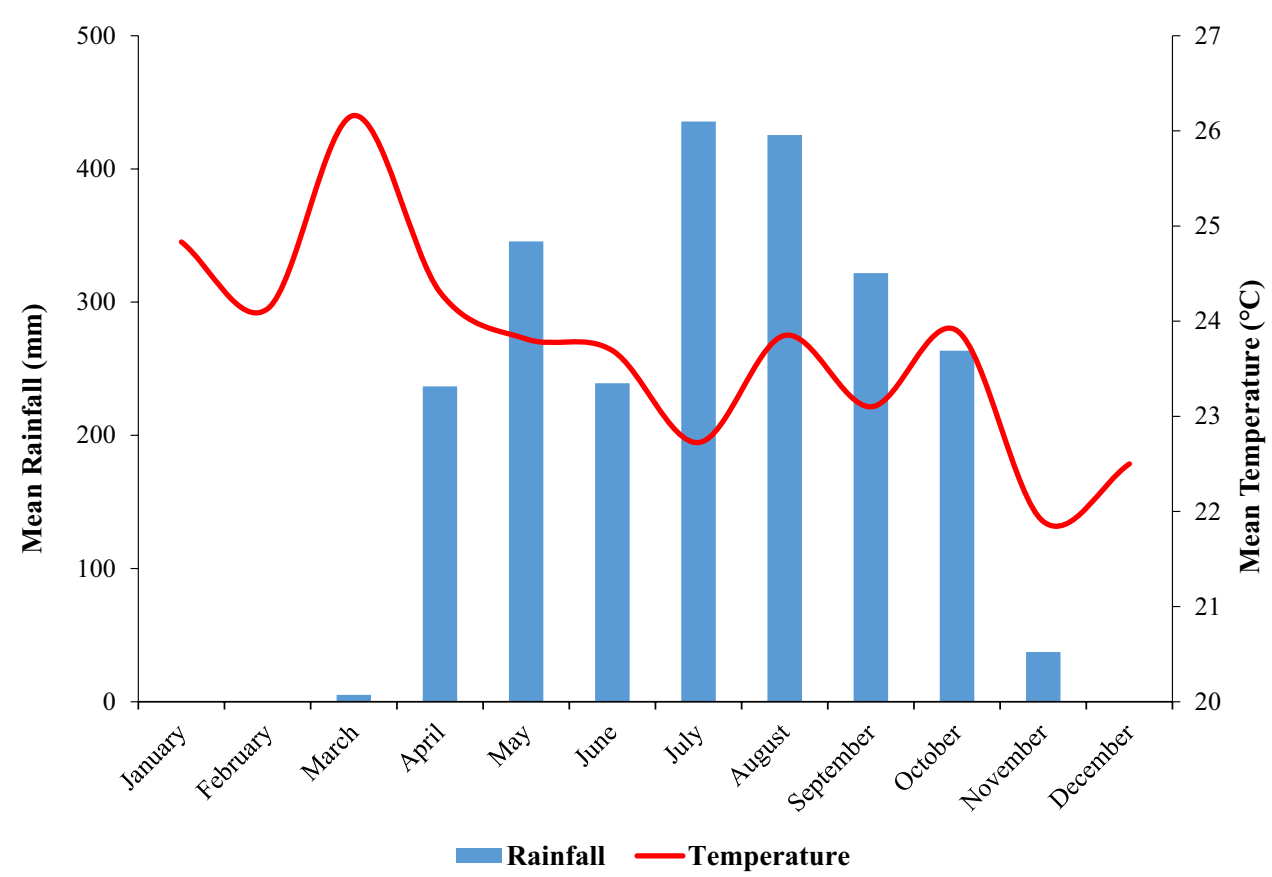


2003). We tested the suitability of the models by comparing the Akaike's Information Criterion (AIC) values and the residual deviance. Furthermore, we tested the model accuracy by assessing the area under the curve (AUC). We derived the mean nest decay rate and the confidence interval for each model by isolating the $X$ factor from Eq. (1) using the coefficients $\alpha$ and $\beta$ from each logistic regression (Eq. 2).

$X=\frac{\log \left(\frac{1}{Y}-1\right)+\alpha}{-\beta}$.

We also assessed whether or not the other recorded variables influenced the nest decay time. Therefore, we added "precipitation", "topography", and their interactions to each of the models tested previously in a second logistic regression analysis. In each case, we fitted a null model first and we added the other variables sequentially. We did not consider "habitat type" or "altitude" in the models since a high proportion of nests were found in forest and the observed altitude range was minimal (665-854 $\mathrm{m}$ asl). We assumed that with the present sample size, the effect of altitude on the mean nest decay rate would not likely be accurately detectable. We performed a third logistic regression analysis considering only "age" and "precipitation" as predictor variables.

Finally, we converted the nest density calculated in the previous study (Kamgang et al. 2018) to chimpanzee density and abundance by using the local nest decay rate obtained in each model. As in Kamgang et al. (2018), the nest production rate was one nest/day/weaned individual and the proportion of nest builders was one as well. We assessed chimpanzee density using Distance 7.2 software (Buckland et al. 2001; Thomas et al. 2010). For this density assessment, we used data from the 2016 survey as well as the local nest decay rate obtained from the current study. We then compared our results to those found by Kamgang et al. (2018) to show how both the chimpanzee density and abundance varied when different non-local and locally acquired nest decay rates were used, emphasizing the importance of the present study.

\section{Results}

We marked and revisited a total of 309 fresh nests (Table 1) during this study. Among the 296 fresh nests marked in the Ganga region, we were only able to revisit 198 due to time constraints and nest accessibility. We also marked and revisited 111 nests from other high-activity chimpanzee areas to assess the effects of environmental variables on the nest decay rates.
Table 1 State of nests revisited (3 months after nest marking) in the Ganga region and other high-activity chimpanzee areas (HAA)

\begin{tabular}{llll}
\hline Sectors & $\begin{array}{l}\text { Number of nests } \\
\text { revisited }\end{array}$ & $\begin{array}{l}\text { Number of nests } \\
\text { absent }\end{array}$ & $\begin{array}{l}\text { Number } \\
\text { of nests } \\
\text { present }\end{array}$ \\
\hline Ganga region & 198 & 166 & 32 \\
Other HAA & 111 & 46 & 65 \\
Total & 309 & 212 & 97 \\
\hline
\end{tabular}

The results obtained in the first logistic regression analysis showed a clear correlation between "absence/presence" and "age" in the three models $(P<0.0001)$, with the probability of nests still being present decreasing significantly as age increased (Table 2, Fig. 3). The nest decay times $\left(\mu_{\mathrm{X}}\right)$ calculated were 141 [95\% CI (109-186)] days in Model 1, 127 [95\% CI (100-160)] days in Model 2 and 130 [95\% CI (81-207)] days in Model 3 (Table 3). With a wider confidence interval range, Model 3 was less defined compared to Models 1 and 2. However, the three mean decay times obtained were similar. The same AUC was obtained in all Models (0.962) and the AIC was 175.29 in Model 1, 127.25 in Model 2, and 130.57 in Model 3. With the lowest AIC, we considered Model 2 the best model fitting the logistic regression curve. This model also showed the most reduced residual deviance (123.25) with the negative-inverse-transformation, followed by Model 3 with the negative-reciprocal-root-transformation (126.57), and finally Model 1 with no transformation of data (153.29).

In the second logistic regression analysis, the effects of "topography" and its interactions with other variables were not significant $(P>0.05)$ and hence, they were not considered in the final model (Supplementary File 4). The results obtained from the third logistic regression analysis without "topography" for Model 2 are presented in Table 4. With regards to the first logistic regression analysis, the variable "age" showed a strong effect on the decaying probability of nests $(P<0.0001)$. The effect of "precipitation" was also significant $(P=0.034)$, increasing the probability of nest decay as the total rainfall in the first month increases (Fig. 4a). Under low monthly rainfall $(0-120 \mathrm{~mm})$ the mean value of "absence/presence" was 0.47 , which decreased below 0.2 when the monthly rainfall was higher (>120 mm) (Fig. 4b). However, the interaction "age* precipitation" was not significant $(P>0.05)$. The nest age also influenced the probability of nest decay, especially during the first month of the nest (Fig. 5a, b). (Supplementary File 5).

We assessed the chimpanzee density using a nest decay rate of 127 days from the most suitable model (Model 2), and obtained a value of 0.59 [95\% CI (0.41-0.86)] chimpanzees $/ \mathrm{km}^{2}$ with an abundance of 987 [95\% CI (683-1427) weaned chimpanzees. We then compared these results to those obtained from the 2016 survey (Table 5). 
Table 2 Results obtained from fitting the three logistic regression models considering "absence/presence" as the response variable and "age" as the predictor variable

\begin{tabular}{|c|c|c|c|c|c|c|c|}
\hline Models & $\begin{array}{l}\text { Residual devi- } \\
\text { ance }\end{array}$ & $\begin{array}{l}\text { Deviance } \\
\text { change }\end{array}$ & $\mathrm{df}$ & df change & $P$ & AIC* & AUC** \\
\hline \multicolumn{8}{|l|}{ Model 1} \\
\hline Null & 367.35 & & 308 & & & 175.29 & 0.962 \\
\hline+ Age & 153.29 & 214.06 & 307 & 1 & $<0.0001$ & & \\
\hline \multicolumn{8}{|l|}{ Model 2} \\
\hline Null & 367.35 & & 308 & & & 127.25 & 0.962 \\
\hline$+(-1 /$ age $)$ & 123.25 & 244.06 & 307 & 1 & $<0.0001$ & & \\
\hline \multicolumn{8}{|l|}{ Model 3} \\
\hline Null & 367.35 & & 308 & & & 130.57 & 0.962 \\
\hline$+(1 / \sqrt{ }$ age $)$ & 126.57 & 240.78 & 307 & 1 & $<0.0001$ & & \\
\hline
\end{tabular}

*Akaike information criterion

**Area under curve
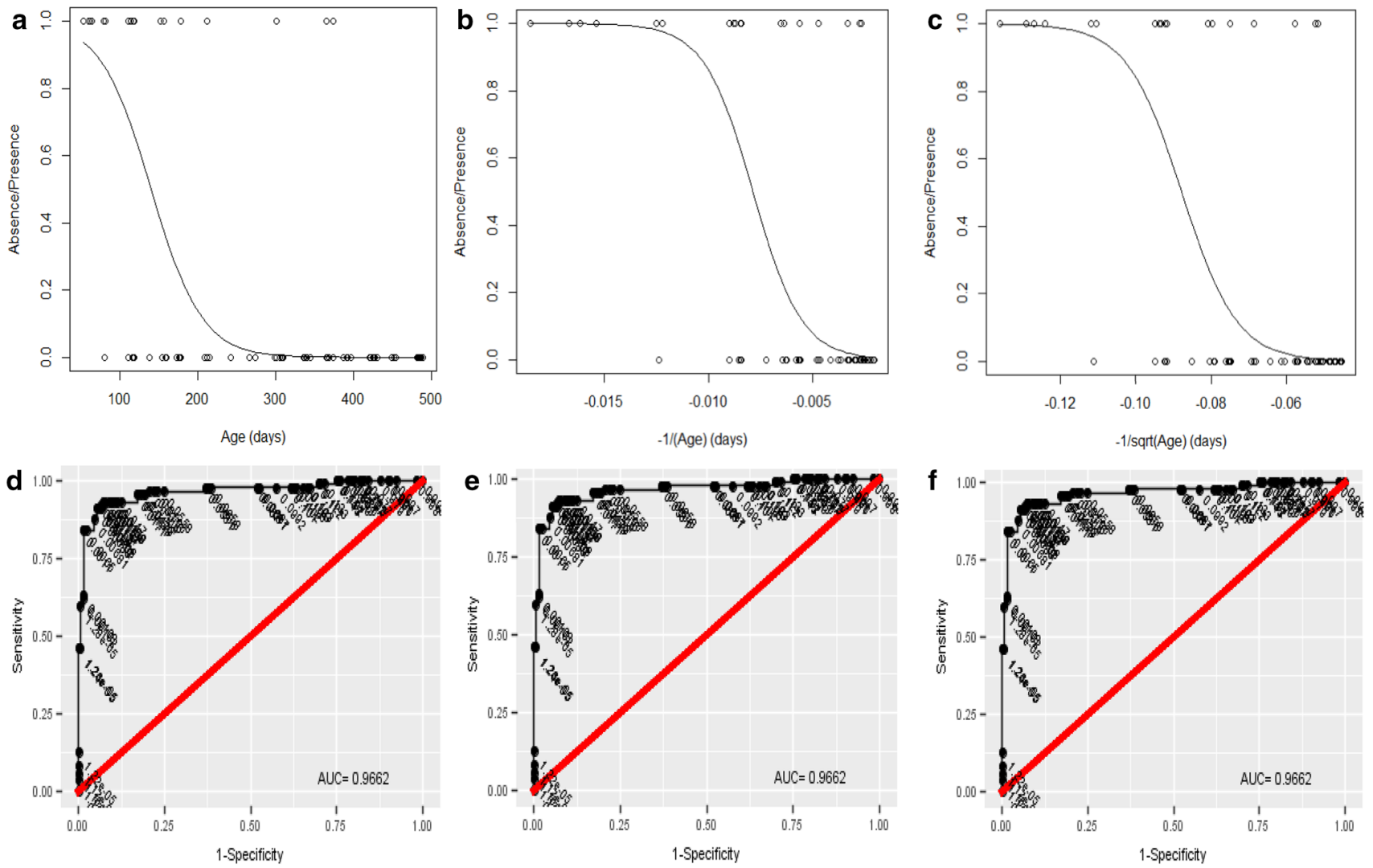

Fig. 3 The effects of nest age on the probability of nest decay. At the top, the logistic regression curves fitted under the three models: a Model 1, b Model 2, and c Model 3. The dots show the recorded

\section{Discussion}

Techniques for estimating the abundance and population status of chimpanzee using nests are well known. Most studies still rely on non-locally derived nest production observations, being 1 for present nests and 0 for decayed nests. At the bottom, the ROC curves (d-f) under the respective model they belong to, and their corresponding AUC value

and decay rates, making the derived great ape densities questionable. In this study, we assessed the nest decay rate for chimpanzees in MDNP and tested the influence of some factors on this parameter. The obtained value allowed us to estimate with greater accuracy the density 
Table 3 Estimated mean nest decay time $\left(\mu_{\mathrm{X}}\right)$ with the $95 \%$ confidence interval (CI) for each model

\begin{tabular}{lll}
\hline Models & $\mu_{X}$ (days) & 95\% CI \\
\hline Model 1 & 141 & {$[109-185]$} \\
Model 2 & 127 & {$[100-160]$} \\
Model 3 & 130 & {$[81-207]$} \\
\hline
\end{tabular}

In Model $1, X$ is non-transformed while in Model 2, $X$ is negative-inverse transformed and in Model 3, $X$ is negativereciprocal root-transformed of chimpanzees in the MDNP, which could to be useful for the long-term monitoring of populations across the park and adjacent areas.

The calculations of the probability of decay of chimpanzee nests is mainly based on nest age, although other factors such as precipitation, topography, and plant material could be important (Laing et al. 2003; Walsh and White 2005; Mathewson et al. 2008). Our mean nest decay rates were similar to those found in Campo Ma' an National Park (south-western Cameroon, $420 \mathrm{~km}$ from MDNP), estimated at 130 days (Matthews and Matthews 2004), as well as in Lopé National Park (Gabon, 710 km from MDNP), estimated at 114 days (Tutin and Fernandez 1984). In contrast, very different decay rates have been found at other sites such as 46 days at Budongo Forest (Uganda, $2150 \mathrm{~km}$ from MDNP) (Plumptre and Reynolds 1996), 90 days at Nouabalé-Ndoki National Park (Republic of Congo, $564 \mathrm{~km}$ from MDNP) (Morgan et al. 2006), and 88 days at Ebo Forest, Cameroon (250 km from MDNP) (Ndimbe et al. 2013). Such variation in nest decay rates despite proximity and similarity in habitat highlights the need for the acquisition of local nest decay rates. Although it is recommended whenever possible that decay rates be used from the same area and same time period as the survey data (Plumptre and Reynolds 1996; Ndimbe et al. 2013; Nzooh et al. 2015), we had no option but to use survey data collected from a different time than the present study. Our study aimed at assessing the nest decay rate for MDNP, which could be used to assess chimpanzee density in the area instead of using a non-local nest decay rate. Furthermore, testing other survey techniques such as mark nest count
(Plumptre and Cox 2006; Ndimbe et al. 2013) and camera trap sampling (Howe et al. 2017; Agha et al. 2018), which do not depend on nest decay rates, are also important for achieving a reliable density estimate (Mathewson et al. 2008).

From our best fitted model (Model 2), there was no evidence of a significant direct correlation between the probability of nest decay and "topography". The latter is a potentially overlooked variable which may influence tree cover and thus the availability of plants used for nesting and should be considered in future studies (Devos et al. 2008). Rainfall had an effect on the mean nest decay rate in the MDNP, increasing the probability of nest decay in the first month of the nest's existence. The effects of rainfall on nest and dung decay rates have been reported in several studies (Barnes et al. 1997; Nchanji and Plumptre 2001; Walsh and White 2005; Ndimbe 2013). With older nests, the probability of decay increases dramatically with little or no effect of rainfall. As the monthly and annual precipitation fluctuates enormously between regions, it is important to take into account that this effect can vary strongly between sites, even when they are located in close proximity to one another (Walsh and White 2005).

Chimpanzee density and abundance in this study were similar to previous estimates in the MDNP (Maisels et al. 2009; Kamgang et al. 2018). These previous studies highlighted the magnitude of the variation in estimates based on the nest decay rate used, and how unreliable the density and abundance estimated might be when non-local nest decay rates are used to convert nest density into chimpanzee density. As many authors have reported, density estimates may be severely biased when using non-locally determined nest decay rates (Laing et al. 2003; Wich et al. 2004; Stokes et al. 2010). When using a mean nest decay rate of 120 days, our results are similar to those of the previous studies in MDNP. However, when comparing the extreme values (88 and 221 days) considered by Kamgang et al. (2018), the density and abundance of the chimpanzees were overestimated using 88 days, and underestimated using 221 days. Therefore, the assessment of locally determined nest decay rates is a crucial priority when applying the SCNC method for chimpanzee surveys.

Table 4 Results obtained from fitting the logistic regression model considering "absence/presence" as the response variable and "age" and "precipitation" as predictor variables

\begin{tabular}{|c|c|c|c|c|c|c|c|}
\hline Model 2 & $\begin{array}{l}\text { Residual devi- } \\
\text { ance }\end{array}$ & $\begin{array}{l}\text { Deviance } \\
\text { change }\end{array}$ & $\mathrm{df}$ & df change & $P$ & AIC & AUC \\
\hline \multicolumn{8}{|c|}{ Negative-inverse transformed } \\
\hline Null & 367.35 & & 308 & & & & \\
\hline$+(-1 /$ Age $)$ & 123.25 & 244.10 & 307 & 1 & $<0.0001$ & 124.77 & 0.966 \\
\hline+ Precipitation & 118.77 & 4.48 & 306 & 1 & 0.034 & & \\
\hline
\end{tabular}



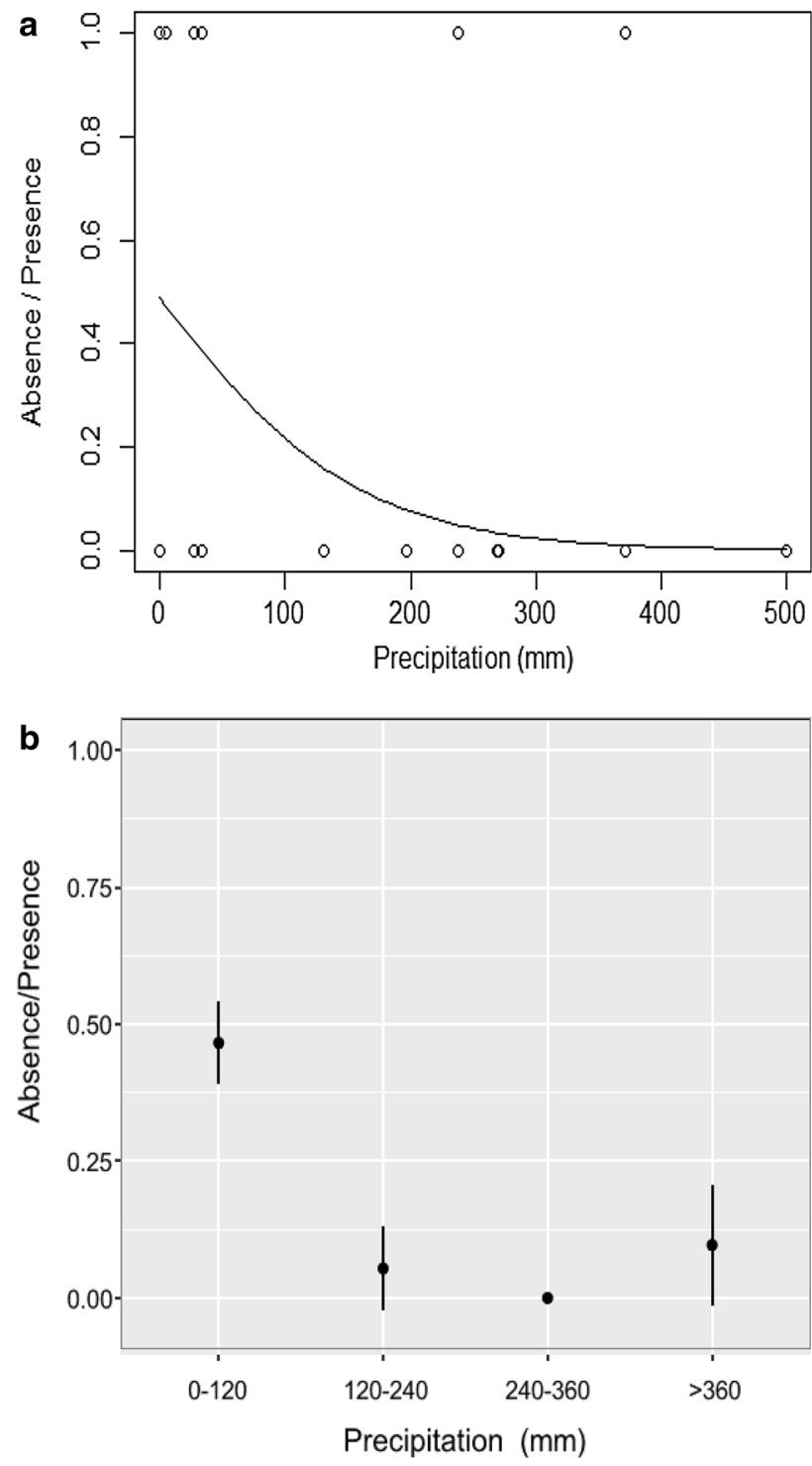

Fig. 4 a The effects of "precipitation" on the probability of nest decay (logistic regression curve of "precipitation" fitted to nest data). b The effects of "precipitation" on the probability of nest decay ("absence/presence" mean value and its 95\% confidence interval considering four ranges of the variable "precipitation" corresponding to the total rainfall during the first month of the nests: $0-120 \mathrm{~mm}, 120$ $240 \mathrm{~mm}, 240-360 \mathrm{~mm}$, and $>360 \mathrm{~mm}$ )

It is also important to highlight that the heterogeneity in the nest decay rate may not only depend on the fluctuation of the climatic factors (such as rainfall), but other variables such as the nesting materials (tree species) and nest height (Laing et al. 2003; Wich et al. 2004; Mathewson et al. 2008). Also, factors like lignin content and the location of the nest in the tree may be considered as other factors which might influence nest decay rate and should be the focus of further investigations. In this study, we
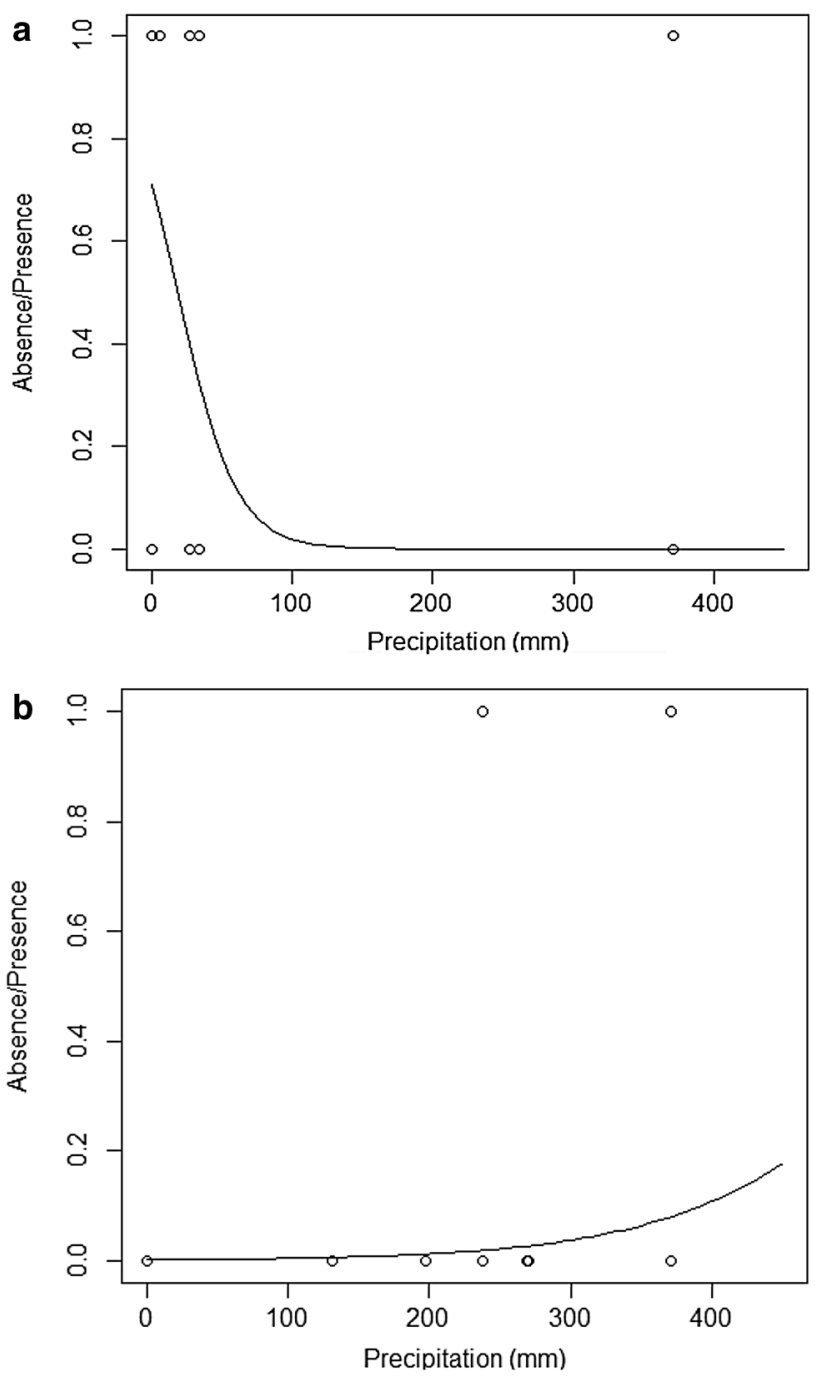

Fig. 5 a The effects of the interaction "Age*Precipitation" (logistic regression curve of "Precipitation" fitted to nest data considering a nest age found between 0 and 250 days). $\mathbf{b}$ The effects of the interaction "age* precipitation" (logistic regression curve of "precipitation" fitted to nest data considering a nest age above 250 days)

were only able to evaluate a small region compared to the extent of the entire national park.

The presence of the forest-savannah mosaic in MDNP increases the heterogeneity of both habitat characteristics and climatic conditions even more (Abwe et al. 2019) and, consequently, might also increase the geographical heterogeneity of the mean nest decay rate. At Ugalla, Tanzania, Stewart et al. (2011) and Hernandez-Aguilar et al. (2013) showed how environmental characteristics determined the nesting site choice, highlighting the effects of habitat heterogeneity on the nest decay rate variation. We recommend more surveys to be conducted in the forest-savannah mosaic area since few fresh nests were found in this habitat during our study. The use of the SCNC technique using locally 
Table 5 Chimpanzee density and abundance at the core area of MDNP and their respective $95 \%$ confidence interval $(\mathrm{CI})$ for each mean decay time

\begin{tabular}{llll}
\hline $\begin{array}{l}\text { Nest decay time } \\
\text { days })\end{array}$ & Chimpanzees/km ${ }^{2}[\mathrm{CI}]$ & Chimpanzee abundance $[\mathrm{CI}]$ & Studies \\
\hline 88 & $0.83[0.32-2.11]$ & $1396[535-3643]$ & (Kamgang et al. 2018) \\
120 & $0.61[0.23-1.59]$ & $1026[397-2650]$ & \\
221 & $0.33[0.12-0.86]$ & $557[216-1439]$ & Present study \\
127 & $0.59[0.41-0.86]$ & $987[683-1427]$ & \\
130 & $0.58[0.40-0.84]$ & $964[667-1394]$ & \\
141 & $0.53[0.37-0.77]$ & $889[615-1285]$ & \\
\hline
\end{tabular}

acquired nest production and decay rates to estimate nest and animal densities is valuable in reducing biases in the long term. One strategy to avoid temporal heterogeneity biases of the nest decay rate could be to estimate correlations between decay rate and factors influencing this parameter such as habitat, rainfall, and nesting material. It might thus be possible to estimate the decay rate in a given time interval based on data obtained from these covariates during the period in which the survey was performed (Barnes et al. 1997). An effective solution to detect population trends and changes in population size is to carry out surveys repeatedly over long periods of time (Morgan et al. 2006). In addition, Mathewson et al. (2008) suggested enhancing the detection of shortterm population changes by monitoring the main threats to the species at each site. Hence, an indirect estimation of the population variation could be obtained by measuring the magnitude of the fluctuations of these threats. We hope that by providing this local nest decay rate, our findings may help the MDNP management to more accurately assess chimpanzee population densities in order to shape their conservation strategies. Also, these results could alert other researchers to the importance of assessing site-specific nest decay rates over the distribution range of great ape species, which will be crucial to making accurate comparisons of population abundance across the landscape.

\section{Conclusions}

In the present study, we estimated an in situ nest decay rate of 127 [95\% (100-160)] days, for an estimated abundance of about 987 [95\% (683-1427)] weaned chimpanzees in MDNP. With this figure, the MDNP should be considered as a site of exceptional priority for the conservation of Nigeria-Cameroon chimpanzee, given the large area of potential habitat and the long-term potential of the site (Morgan et al. 2011). Rainfall in a warm tropical region such as this plays an important role over the first period of a nest's lifetime, significantly increasing the probability of nest decay. Other factors such as type of habitat or tree species should be considered in future studies, since they may also have effects on the mean nest decay rate
(Laing et al. 2003; Walsh and White 2005; Mathewson et al. 2008). In order to improve the accuracy and precision of nest decay rates and density estimates, a larger area should be surveyed to obtain a more representative nest sample size for the whole national park and thus reduce the source of error based on spatial fluctuations of the nest decay rate. We recommend that researchers carry out repeated surveys over time in order to minimize the problem of temporal heterogeneity of this parameter as well as to detect short-term fluctuations of chimpanzee population densities (Maisels et al. 2009; Morgan et al. 2011). Finally, both the use of site-specific parameters as well as efficient threat mitigation are essential tasks for an effective management and conservation of great ape populations throughout their range.

Acknowledgements We thank the country director of Wildlife Conservation Society Biodiversity Conservation Program, Dr. Roger Fotso, the WCS Mbam-Djerem National Park (MDNP) project manager, Mr. Bernard Fosso, and the conservator of the MDNP, Mr. Albert Mounga, for their collaboration and logistical support during fieldwork. Thanks also to Dr. Fiona Maisels for providing the inspiration for this study. Analyses were conducted as part of the Ph.D. dissertation of the first author, which was funded by WWF Russell E. Train Education for Nature and the Rufford Foundation for Nature Conservation. We also thank Dr. Jorgelina Marino, Dr. Paul Johson, Dr. Zacharie Nzooh Dongmo, and Dr. Julia Baum for their comments on initial drafts, and the editor and reviewers for their helpful comments.

Authors contributions SAK, KSB, MKG, and BS designed the research. SAK and EE Abwe marked the nests. SAK and CTC revisited the marked nests and performed data analysis. SAK and CT wrote and revised the manuscript. All of the authors read and approved the final manuscript.

Funding This research was funded by grants awarded to Serge Alexis Kamgang from WWF Russell E. Train Education for Nature (Agreement \#ST62) and the RSG Foundation (RSG 13184-2). The founders had no role in study design, data collection and analysis, and 505 decision to publish the findings.

\section{Compliance with ethical standards}

Conflict of interest The author(s) declares that they have no conflict of interest.

Our relationship with World Wide Fund for Nature (WWF) and Rufford Small Grant (RSG) Foundation is simply that of a donor/grantee 
relation. This does not hinder our commitment to the editorial policies of Elsevier on publishing findings, data, and materials.

Consent for publication Not applicable.

Ethics approval and consent to participate This was a non-invasive study conducted in the Mbam-Djerem National Park using only indirect observations of chimpanzee (nests), within the framework of a PhD research program. The research program was implemented in collaboration with the Ministry of Forestry and Wildlife, the Wildlife Conservation Society (WCS-Cameroon) and the University of Abomey-Calavi in Bénin.

Open Access This article is distributed under the terms of the Creative Commons Attribution 4.0 International License (http://creativeco mmons.org/licenses/by/4.0/), which permits unrestricted use, distribution, and reproduction in any medium, provided you give appropriate credit to the original author(s) and the source, provide a link to the Creative Commons license, and indicate if changes were made.

\section{References}

Abwe EE, Morgan BJ, Tchiengue B, Kentatchime F, Doudja R, Ketchen ME, Teguia E, Ambahe R, Venditti DM, Mitchell MW (2019) Habitat differentiation among three Nigeria-Cameroon chimpanzee (Pan troglodytes ellioti) populations. Ecol Evolut. https://doi.org/10.1002/ece3.4871

Agha M, Batter T, Bolas EC, Collins AC, Gomes da Rocha D, Monteza-Moreno CM, Preckler-Quisquater S, Sollmann R (2018) A review of wildlife camera trapping trends across Africa. Afr J Ecol 56:694-701. https://doi.org/10.1111/aje.12565

Anderson JR (2000) Sleep-related behavioral adaptations in free-ranging anthropoid primates. Sleep Med Rev 4:355-373. https://doi. org/10.1053/smrv.2000.0105

Barnes R, Dunn A (2002) Estimating forest elephant density in Sapo National Park (Liberia) with a rainfall model. Afr J Ecol 40:159_ 163. https://doi.org/10.1046/j.1365-2028.2002.00362.x

Barnes R, Asamoah-Boateng B, Naada Majam J, Agyei-Ohemeng J (1997) Rainfall and the population dynamics of elephant dungpiles in the forests of southern Ghana. Afr J Ecol 35:39-52. https ://doi.org/10.1111/j.1365-2028.1997.061-89061.x

Bermejo M, Rodríguez-Teijeiro JD, Illera G, Barroso A, Vilà C, Walsh PD (2006) Ebola outbreak killed 5000 gorillas. Science 314:1564. https://doi.org/10.1126/science.1133105

Bobo KS, Weladji RB (2011) Wildlife and land use conflicts in the Mbam and Djerem conservation region, Cameroon: status and mitigation measures. Hum Dimens Wildl 16:445-457. https://doi. org/10.1080/10871209.2011.608219

Bobo KS, Eddie W, Anye ND, Njie MF, Fotso RC, Languy M (2006) The birds of Mbam and Djerem National Park, Cameroon. Malimbus 28:90-106

Buckland ST, Anderson DR, Burnham KP, Laake JL, Borchers DL, Thomas L (2001) Introduction to distance sampling estimating abundance of biological populations

Buij R, Singleton I, Krakauer E, Van Schaik C (2003) Rapid assessment of orangutan density. Biol Cons 114:103-113. https://doi. org/10.1016/S0006-3207(03)00015-6

Caldecott JO, Miles L (2005) World atlas of great apes and their conservation. Univ of California Press, California

Cameron KN, Reed P, Morgan DB, Ondzié AI, Sanz CM, Kühl HS, Olson SH, Leroy E, Karesh WB, Mundry R (2016) Spatial and temporal dynamics of a mortality event among Central African
Great Apes. PLoS One 11:e0154505. https://doi.org/10.1371/ journal.pone.0154505

De Wasseige C, De Marcken P, Bayol N, Hiol-Hiol F, Mayaux P, Desclée B, Nasi R, Billand A, Defourny P, Atyi EA (2012) The forests of the Congo Basin: state of the forest 2010. Publ Off Eur Union Luxemb. https://doi.org/10.2788/47210

Devos C, Walsh PD, Arnhem E, Huynen M-C (2008) Monitoring population decline: can transect surveys detect the impact of the Ebola virus on apes? Oryx 42:367-374. https://doi.org/10.1017/ S0030605308000161

Dutton PE (2012) Chimpanzee (Pan troglodytes ellioti) ecology in a Nigerian montane forest. Ph.D. Thesis, University of Canterbury. https://ir.canterbury.ac.nz/handle/10092/8187. Accessed 4 Sep 2016

Fay JM (1991) An elephant (Loxodonta africana) survey using dung counts in the forests of the Central African Republic. J Trop Ecol 7:25-36. https://doi.org/10.1017/S0266467400005022

Fruth B, Hohmann G (1996) Nest building behavior in the great apes: the great leap forward? Great Ape Soc 225

Gonder MK, Oates JF, Disotell TR, Forstner MR, Morales JC, Melnick DJ (1997) A new west African chimpanzee subspecies? Nature 388:337

Gonder MK, Disotell TR, Oates JF (2006) New genetic evidence on the evolution of chimpanzee populations and implications for taxonomy. Int J Primatol 27:1103-1127

Gonder M, Locatelli S, Ghobrial L, Sheppard A (2009) The genetic history of chimpanzees across the Gulf of Guinea region. Wiley, Hoboken, p 136 (American Journal of Physical Anthropology)

Guinness P (2010) Geography for the IB diploma patterns and change. Cambridge University Press, Cambridge

Hart JA, Grossmann F, Vosper A, Ilanga J (2008) Human hunting and its impact on bonobos in the Salonga National Park, Democratic Republic of Congo. Springer, The Bonobos, pp 245-271. https:// doi.org/10.1007/978-0-387-74787-3_13

Hashimoto C (1995) Population census of the chimpanzees in the Kalinzu Forest, Uganda: comparison between methods with nest counts. Primates 36:477-488. https://doi.org/10.1007/BF023 82870

Haurez B, Petre C-A, Vermeulen C, Tagg N, Doucet J-L (2014) Western lowland gorilla density and nesting behavior in a Gabonese forest logged for 25 years: implications for gorilla conservation. Biodivers Conserv 23:2669-2687. https://doi.org/10.1007/s1053 1-014-0743-1

Head JS, Boesch C, Robbins MM, Rabanal LI, Makaga L, Kühl HS (2013) Effective sociodemographic population assessment of elusive species in ecology and conservation management. Ecol Evolut 3:2903-2916. https://doi.org/10.1002/ece3.670

Hernandez-Aguilar RA, Moore J, Stanford CB (2013) Chimpanzee nesting patterns in savanna habitat: environmental influences and preferences. Am J Primatol 75:979-994. https://doi.org/10.1002/ ajp. 22163

Hicks T, Darby L, Hart J, Swinkels J, January N, Menken S (2010) Trade in orphans and bushmeat threatens one of the Democratic Republic of the Congo's most important populations of eastern chimpanzees (Pan troglodytes schweinfurthii). Afr Primates (Print) $7: 1-18$

Hicks TC, Tranquilli S, Kuehl H, Campbell G, Swinkels J, Darby L, Boesch C, Hart J, Menken SB (2014) Absence of evidence is not evidence of absence: discovery of a large, continuous population of Pan troglodytes schweinfurthii in the Central Uele region of northern DRC. Biol Cons 171:107-113. https://doi.org/10.1016/j. biocon.2014.01.002

Howe EJ, Buckland ST, Després-Einspenner ML, Kühl HS (2017) Distance sampling with camera traps. Methods Ecol Evol 8:15581565. https://doi.org/10.1111/2041-210X.12790 
Huijbregts B, De Wachter P, Obiang LSN, Akou ME (2003) Ebola and the decline of gorilla Gorilla gorilla and chimpanzee Pan troglodytes populations in Minkebe Forest, north-eastern Gabon. Oryx 37:437-443. https://doi.org/10.1017/S0030605303000802

Humle T, Maisels F, Oates JF, Plumptre A, Williamson EA (2016). Pan troglodytes. The IUCN Red List of threatened species. e.T15933A102326672. http://dx.doi.org/10.2305/IUCN. UK.2016-2.RLTS.T15933A17964454.en. Accessed 31 March 2017

IUCN (2014) Regional action plan for the conservation of Western Lowland Gorillas and Central Chimpanzees 2015-2025. IUCN SSC Primate Specialist Group, Switzerland, p 56

Jathanna D, Karanth KU, Kumar NS, Goswami VR, Vasudev D, Karanth KK (2015) Reliable monitoring of elephant populations in the forests of India: analytical and practical considerations. Biol Cons 187:212-220. https://doi.org/10.1016/j.biocon.2015.04.030

Kalan AK, Piel AK, Mundry R, Wittig RM, Boesch C, Kühl HS (2016) Passive acoustic monitoring reveals group ranging and territory use: a case study of wild chimpanzees (Pan troglodytes). Front Zool 13:34. https://doi.org/10.1186/s12983-016-0167-8

Kamgang SA, Bobo KS, Maisels F, Ambahe RDD, Ongono DEA, Gonder MK, Johnson P, Marino J, Sinsin B (2018) The relationship between the abundance of the Nigeria-Cameroon chimpanzee (Pan troglodytes ellioti) and its habitat: a conservation concern in Mbam-Djerem National Park, Cameroon. BMC Ecol 18:40. https ://doi.org/10.1186/s12898-018-0199-3

Katsis L, Cunneyworth PM, Turner KM, Presotto A (2018) Spatial patterns of primate electrocutions in Diani, Kenya. Int J Primatol 39:493-510. https://doi.org/10.1007/s10764-018-0046-6

Kingdon J, Largen M (1997) The kingdom field guide to African mammals. Zool J Linn Soc 120:479

Koops K, McGrew WC, Matsuzawa T, Knapp LA (2012) Terrestrial nest-building by wild chimpanzees (Pan troglodytes): implications for the tree-to-ground sleep transition in early hominins. Am J Phys Anthropol 148(3):351-361. https://doi.org/10.1002/ ajpa.22056

Krebs CJ (1989) Ecological methodology. Harper \& Row, New York

Kühl H (2008) Best practice guidelines for the surveys and monitoring of great ape populations. IUCN. IUCN SSC Primate Specialist Group, Switzerland

Laing S, Buckland S, Burn R, Lambie D, Amphlett A (2003) Dung and nest surveys: estimating decay rates. J Appl Ecol 40:1102-1111. https://doi.org/10.1111/j.1365-2664.2003.00861.x

Maisels F, Fotso R, Hoyle D (2000) Conservation status, large mammals and human impact. Report wildlife conservation society, Cameroon program. Mbam Djerem National Park, Yaoundé

Maisels F, Ambahe E, Ambassa R, Nyemgah Yara C, Fosso B (2009) Great Ape and human impact monitoring in the Mbam et Djerem National Park, Cameroon. Final report to USFWS-GACF Agreement 98210-7-G290. Wildlife Conservation Society, New York

Mathewson P, Spehar S, Meijaard E, Sasmirul A, Marshall AJ (2008) Evaluating orangutan census techniques using nest decay rates: implications for population estimates. Ecol Appl 18:208-221. https://doi.org/10.1890/07-0385.1

Matthews A, Matthews A (2004) Survey of gorillas (Gorilla gorilla gorilla) and chimpanzees (Pan troglodytes troglodytes) in Southwestern Cameroon. Primates 45:15-24. https://doi.org/10.1007/ s10329-003-0058-4

MINFOF (2007) Plan d'aménagement du Parc National du Mbam et Djerem et sa zone périphérique. 2007-2011

Mitchell MW, Locatelli S, Ghobrial L, Pokempner AA, Clee PRS, Abwe EE, Nicholas A, Nkembi L, Anthony NM, Morgan BJ (2015) The population genetics of wild chimpanzees in Cameroon and Nigeria suggests a positive role for selection in the evolution of chimpanzee subspecies. BMC Evol Biol 15:1. https://doi. org/10.1186/s12862-014-0274-0
Morgan D, Sanz C, Onononga JR, Strindberg S (2006) Ape abundance and habitat use in the Goualougo Triangle, Republic of Congo. Int J Primatol 27:147-179. https://doi.org/10.1007/s1076 4-005-9013-0

Morgan BJ, Adeleke A, Bassey T, Bergl R, Dunn A, Fotso R, Gadsby E, Gonder MK, Greengrass E, Koulagna DK (2011) Regional action plan for the conservation of the Nigeria-Cameroon chimpanzee (Pan troglodytes ellioti). 0911461000, IUCN/SSC Primate Specialist Group and Zoological Society of San Diego

Nchanji AC, Plumptre AJ (2001) Seasonality in elephant dung decay and implications for censusing and population monitoring in south-western Cameroon. Afr J Ecol 39:24-32. https://doi.org/ 10.1111/j.1365-2028.2001.00265.x

Ndimbe MS, Morgan BJ, Marino J, Abwe AEE (2013) Population density estimate of the Nigeria-Cameroon Chimpanzee (Pantroglodytes ellioti) in the Ebo forest, Cameroon. report WildCRU, Oxford University. UK:23

Nkono J, Tchamba M, Nzooh Dongmo Z, N'goran KP (2015) Durées moyennes de vie des crottes d'éléphants et des nids de grands singes, et application dans l'estimation de leurs densités dans l'UTO Campo-Ma'an. Engineering thesis. University of Dschang, Cameroon, pp 41

Nzooh Z, N'Goran K, Fondja C, Nkono J (2015) Evaluation de la dynamique des populations de grands et moyens mammifères dans le domaine forestier permanent de l'Unité Technique Opérationnelle Campo Ma'an. Biomonitoring report. World Wide Fund for Nature_WWF Cameroon, pp 103

Oates JF, Doumbe O, Dunn A, Gonder MK, Ikemeh R, Imong I, Morgan BJ, Ogunjemite B, Sommer V (2016) Pan troglodytes ssp. ellioti. The IUCN Red List of Threatened Species. e.T40014A17990330. http://dx.doi.org/10.2305/IUCN. UK.2016-2.RLTS.T40014A17990330.en. Accessed 20 Oct 2016

Plumptre AJ (2000) Monitoring mammal populations with line transect techniques in African forests. J Appl Ecol 37:356-368. https://doi.org/10.1046/j.1365-2664.2000.00499.x

Plumptre AJ, Cox D (2006) Counting primates for conservation: primate surveys in Uganda. Primates 47:65-73

Plumptre A, Reynolds V (1996) Censusing chimpanzees in the Budongo forest, Uganda. Int J Primatol 17:85-99. https://doi. org/10.1007/BF02696160

Prado-Martinez J, Sudmant PH, Kidd JM, Li H, Kelley JL, LorenteGaldos B, Veeramah KR, Woerner AE, O'connor TD, Santpere G (2013) Great ape genetic diversity and population history. Nature 499:471. https://doi.org/10.1038/nature12228

Pruetz JD, Fulton S, Marchant LF, McGrew WC, Schiel M, Waller M (2008) Arboreal nesting as anti-predator adaptation by savanna chimpanzees (Pan troglodytes verus) in southeastern Senegal. Am J Primatol 70(4):393. https://doi.org/10.1002/ajp.20508

Samson DR, Hunt KD (2012) A thermodynamic comparison of arboreal and terrestrial sleeping sites for dry-habitat chimpanzees (Pan troglodytes schweinfurthii) at the Toro-Semliki Wildlife Reserve, Uganda. Am J Primatol 74:811-818. https://doi. org/10.1002/ajp.22138

Serckx A, Huynen M-C, Bastin J-F, Hambuckers A, Beudels-Jamar RC, Vimond M, Raynaud E, Kühl HS (2014) Nest grouping patterns of bonobos (Pan paniscus) in relation to fruit availability in a forest-savannah mosaic. PLoS One 9:e93742. https://doi. org/10.1371/journal.pone.0093742

Sesink-Clee PR, Abwe EE, Ambahe R, Anthony NM, Fotso R, Locatelli S, Maisels F, Mitchell MW, Morgan BJ, Pokempner A (2015) Chimpanzee population structure in Cameroon and Nigeria is associated with habitat variation that may be lost under climate change. BMC Evol Biol. https://doi.org/10.1186/ s12862-014-0275-Z 
Singleton I (2009) Ranging behaviour of orangutan females and social organization. In: Wich SA, Utami S, Mitra Setia T, Van Schaik CP (eds) Orangutans: geographic variation in behavioral ecology and conservation. Oxford University Press, Oxford, pp 204-214

Spehar SN, Mathewson PD, Nuzuar, Wich SA, Marshall AJ, Kühl H, Nardiyono, Meijaard E (2010) Estimating orangutan densities using the standing crop and marked nest count methods: lessons learned for conservation. Biotropica 42(6):748-757. https://doi. org/10.1111/j.1744-7429.2010.00651.x

Stewart FA, Piel AK, McGrew W (2011) Living archaeology: artefacts of specific nest site fidelity in wild chimpanzees. J Hum Evol 61:388-395. https://doi.org/10.1016/j.jhevol.2011.05.005

Stokes EJ, Strindberg S, Bakabana PC, Elkan PW, Iyenguet FC, Madzoké B, Malanda GAF, Mowawa BS, Moukoumbou C, Ouakabadio FK (2010) Monitoring great ape and elephant abundance at large spatial scales: measuring effectiveness of a conservation landscape. PLoS One 5(4):e10294. https://doi.org/10.1371/journ al.pone.0010294

Thomas L, Buckland ST, Rexstad EA, Laake JL, Strindberg S, Hedley SL, Bishop JR, Marques TA, Burnham KP (2010) Distance software: design and analysis of distance sampling surveys for estimating population size. J Appl Ecol 47:5-14. https://doi.org/ 10.1111/j.1365-2664.2009.01737.x

Tsakem S, Tchamba M, Weladji R (2015) Les gorilles (Gorilla gorilla gorilla, Savage \& Wyman 1847) du parc national de Lobéké (Cameroun). Abondance, utilisation de l'habitat et interactions avec les populations locales. Ph.D. thesis, University of Kinshasa, Democratic Republic of Congo, pp 132

Tutin CE, Fernandez M (1984) Nationwide census of gorilla (Gorilla g. gorilla) and chimpanzee (Pan t. troglodytes) populations in Gabon. Am J Primatol 6:313-336. https://doi.org/10.1002/ ajp. 1350060403

Van Schaik C, Priatna A, Priatna D (1995) Population estimates and habitat preferences of orangutans based on line transects of nests. The neglected ape. Springer, pp 129-147. https://doi. org/10.1007/978-1-4899-1091-2_15

Vernes K (1999) Pellet counts to estimate density of a rainforest kangaroo. Wildlife Society, Bulletin, pp 991-996
Walsh PD, White LJ (2005) Evaluating the steady state assumption: simulations of gorilla nest decay. Ecol Appl 15:1342-1350. https ://doi.org/10.1890/03-5283

Walsh PD, Abernethy KA, Bermejo M, Beyers R, De Wachter P, Akou ME, Huijbregts B, Mambounga DI, Toham AK, Kilbourn AM (2003) Catastrophic ape decline in western equatorial Africa. Nature 422:611. https://doi.org/10.1038/nature01566

WCS (2017) Mbam and Djerem National Park, Cameroon. https:// programs.wcs.org/cameroon/Wild-Places/Mbam-Djerem-Natio nal-Park1.aspx. Accessed 25 April 2017

Wevers D, Metzger S, Babweteera F, Bieberbach M, Boesch C, Cameron K, Couacy-Hymann E, Cranfield M, Gray M, Harris LA, Head J, Jeffery K, Knauf S, Lankester F, Leendertz SAJ, Lonsdorf E, Mugisha L, Nitsche A, Reed P, Robbins M, Travis DA, Zommers Z, Leendertz FH, Ehlers B (2011) Novel adenoviruses in wild primates: a high level of genetic diversity and evidence of zoonotic transmissions. J Virol 85:10774-10784. https://doi. org/10.1128/JVI.00810-11

White F (ed) (1983) The vegetation of Africa: a descriptive memoir to accompany the UNESCO/AETFAT/UNSO vegetation map of Africa. Natural Resources Research Report XX, UNESCO, Paris, France, https://doi.org/10.2307/633318

Wich SA, Utami-Atmoko SS, Setia TM, Rijksen HD, Schürmann C, Van Hooff J, van Schaik CP (2004) Life history of wild Sumatran orangutans (Pongo abelii). J Hum Evol 47:385-398. https://doi. org/10.1007/s10329-004-0080-1

Williamson EA, Maisel FG, Groves CP, Fruth BI, Humle T, Morton FB, Richardson MC, Russon AE, Singleton I (2013) Family Hominidae (great apes). In: Intermediary RA, Irelands AB, Wilson DE (eds) Handbook of the mammals of the world, 3rd edn. Barcelona, Ireland, pp 792-843

Publisher's Note Springer Nature remains neutral with regard to jurisdictional claims in published maps and institutional affiliations. 